\title{
Práctica: elaboración de ensalada cesar
}

Practice: elaboration of cesar salad

Alexia Vázquez Hernández ${ }^{a}$, Jair Emmanuel Onofre Sánchez ${ }^{b}$

\begin{abstract}
:
The Cesar salad has been a dish representative of the service at the table known as French service, also its creation in Tijuana in July 1924 has become an important element in the cuisine, the origin is thanks to Mr. Cardini was the owner of the restaurant that It was located below the hotel Cesar, this creation emerged from the remains of the ingredients of the restaurant now is a dish consumed in many parts of the world.
\end{abstract}

Keywords:

Salad, Cesar, gueridon

Resumen:

La ensalada Cesar ha sido un plato representativo del servicio en la mesa conocido como servicio francés, además su creación en Tijuana en julio de 1924 la ha convertido en un elemento importante de la gastronomía Nacional, el origen es gracias al señor Cardini quien era dueño del restaurante que se ubicaba abajo del hotel Cesar, esta creación surgida de los de los ingredientes del restaurante ahora es un majar consumido en muchas partes del mundo.

Palabras Clave:

Ensalada, Cesar, gueridon

\section{Introducción}

Los datos históricos hablan de que el servicio a la francesa tuvo sus inicios en la corte de Luis VIX, en dónde la función era transportar viandas de plata cubiertas de la cocina hacia el comedor para mantener caliente los alimentos (Culinary Institute of America, 2011), hoy en día el servicio ha sufrido una serie de transformaciones pero la esencia sigue siendo la misma: proveer de un valor agregado el servicio al comensal ya que su elaboración requiere una capacitación especial del dependiente de comedor quien tiene la responsabilidad de preparar o terminar el plato a un lado.

El ahora llamado servicio de gueridon es la prestación en el salón, es un carro móvil que regularmente tiene de un elemento de calor, el réchaud $^{\star}$ y un espacio de preparación para entrants y ensaladas, de igual manera debe de contar con los instrumentos necesarios para que la preparación sea rápida. Una de las ventajas de trabajar con el gueridon, es que el cliente no sólo se entretiene puede observar la inocuidad con la que trabajan sus alimentos (Culinary Institute of America, 2014)

\section{DESARROLLO:}

I. OBJETIVO GENERAL DE LA PRÁCTICA

Elaborar con cuchareo frente al comensal la ensalada Cesar

II. IMPLEMENTOS A UTILIZAR

\footnotetext{
* Utensilio para cocinar o flambear a la vista del cliente, platos que no requieren excesivo cocinado. Pueden ser de gas o alcohol.
} 
Plato trinche, ensaladera, tabla, cuchareo y bowl.

\section{INSUMOS REQUERIDOS PARA SU PREPARACIÓN}

Ingredientes primarios de la ensalada Cesar

\begin{tabular}{|c|c|c|}
\hline Anchoas & 0.020 & $\mathrm{Kg}$ \\
\hline Ajo & 0.010 & $\mathrm{Kg}$ \\
\hline Alcaparras & 0.005 & $\mathrm{Kg}$ \\
\hline Mostaza Dijon & 0.010 & $\mathrm{Kg}$ \\
\hline Huevo & 0.060 & $\mathrm{Kg}$ \\
\hline Limón & 1 & Pza \\
\hline Vinagre de vino & 0.015 & $\mathrm{~L}$ \\
\hline Aceite de olivo & $\mathrm{c} / \mathrm{s}$ & $\mathrm{L}$ \\
\hline Lechugas & 0.200 & $\mathrm{Kg}$ \\
\hline Pimienta de & 0.005 & $\mathrm{Kg}$ \\
\hline \multicolumn{3}{|l|}{-Guarnición- } \\
\hline Crutones & 0.070 & $\mathrm{Kg}$ \\
\hline Queso & 0.040 & $\mathrm{Kg}$ \\
\hline Ânchoas & 0.020 & $\mathrm{Kg}$ \\
\hline Ajo & 0.010 & $\mathrm{Kg}$ \\
\hline Sal & 0.0 & $\mathrm{c} / \mathrm{n}$ \\
\hline
\end{tabular}

\section{PROCEDIMIENTO}

Picar el ajo finamente, desinfectar y trozar las lechugas mixtas. Preparar crotones

Presentar los ingredientes de la ensalada en un plato hondo, se ponen las alcaparras y anchoas y se machacan con un tenedor.

Se agrega el ajo y se vuelve a machacar, se agrega la mostaza y la yema de un huevo. Comenzar a emulsionar la vinagreta, se añade el jugo de medio limón, sal y pimienta al gusto, vinagre de vino blanco y se combina, se mezcla la base de la vinagreta con el aceite a punto de hilo. En un bowl o ensaladera poner una base de la vinagreta mezclando rápidamente para que llegue a todas las hojas.

Emplatar en un plato trinche acompañado de queso parmesano y crotones.

\section{Notas}

Tener cuidado con la cantidad de vinagre ya que un exceso puede opacar el sabor de los demás ingredientes.

\section{CONCLUSIONES}

Se concluye que a partir de los conocimientos adquiridos en el servicio francés, beneficia en el desarrollo de habilidades que son de vital importancia para los estudiantes de gastronomía ya que les permite insertarse en restaurantes de alta gama, al mismo tiempo se puede observar que el conocimiento de las bases históricas de un platillo es fundamental para llevar a cabo su correcta elaboración

\section{Referencias}

[1] The culinary Institute of America (2014). Remarkable Service . New Jersey: Wiley \& sons

[2] The culinary Institute of America. (2011). The Professional Chef (9th ed.). New Jersey, Wiley \& sons 